American Journal of Environmental Sciences 2 (2): 41-48, 2006

ISSN 1553-345X

(C) 2006 Science Publications

\title{
Antagonism Between Chlorpyrifos and Flaxedil in Toad and Earthworm Neuromuscular Transmission
}

\author{
${ }^{1}$ Yong-Chiang Chang, ${ }^{2}$ Amauri B. Bartoszeck, ${ }^{1}$ Samir A. Madeira and ${ }^{3}$ Charles I. Abramson \\ ${ }^{1}$ Instituto de Saúde Bezerra Menezes, Curitiba, Paraná 80011-970, Brazil \\ ${ }^{2}$ Departamento de Fisiologia, Universidade Federal do Paraná, Curitiba, Paraná Brazil \\ ${ }^{3}$ Laboratory of Comparative Psychology and Behavioral Biology \\ Departments of Psychology and Zoology, Oklahoma State University, Stillwater, Oklahoma USA
}

\begin{abstract}
The cholinesterase inhibition effect of chlorpyrifos, a commercial insecticide, was tested by its antagonism to the acetylcholine inhibition effect of flaxedil in 30 isolated nerve-sartorius muscle preparations of the toad, compared with its antagonism in 30 isolated nerve cord-body wall muscle preparations of the earthworm. Inhibition and facilitation in this antagonism were measured by changes in depolarizing rate of toad endplate potential and in earthworm slow potential and by changes in interstimulus interval for evoking an action potential in toad preparations and a graded spike potential in earthworm preparations. Earthworm depolarizing rate $\left(0.32 \mathrm{~V} \mathrm{~s}^{-1}\right)$ in its normal Ringer was five times lower than that $\left(1.50 \mathrm{~V} \mathrm{~s}^{-1}\right)$ of toad under [Flaxedil] $]_{\mathrm{o}}=3 \times 10^{-3} \mathrm{~g} \mathrm{cc}^{-1}$. Earthworm interstimulus interval $(15.6 \mathrm{~ms})$ in its normal Ringer was nine times longer than that $(1.75 \mathrm{~ms})$ of toad under [Flaxedil] $]_{o}=3 \times 10^{-3} \mathrm{~g} \mathrm{cc}^{-1}$. [Flaxedil] o between $3 \times 10^{-4} \mathrm{~g} \mathrm{cc}^{-1}$ and $5 \times 10^{-4} \mathrm{~g} \mathrm{cc}^{-1}$ attenuated $25 \%$ of toad depolarizing rate and $23 \%$ of earthworm depolarizing rate, $60 \%$ of toad interstimulus interval and eliminated the earthworm interstimulus interval almost entirely. Enhancement of toad depolarizing rate and interstimulus interval by chlorpyrifos between $5 \times 10^{-4} \mathrm{~g} \mathrm{cc}^{-1}$ and $10^{-2} \mathrm{~g} \mathrm{cc}^{-1}$ after being attenuated by flaxedil was not significant but was significant in the earthworm preparation. Inhibition of earthworm cholinesterase by chlorpyrifos may be related to its lower neuromuscular excitability than that of the toad.
\end{abstract}

Key words: Chlorpyrifos, flaxedil, depolarizing rate, interstimulus interval, toad endplate potential, earthworm slow potential

\section{INTRODUCTION}

The organophosphate insecticide, Chlorpyrifos, exerts its effect not only on insects but also on human and domestic animals, through several different mechanisms. One of these mechanisms is a facilitated cholinergic synaptic transmission due to inhibition of the enzyme cholinesterase ${ }^{[1-3]}$. The purpose of this article is to test this cholinesterase inhibition by chlorpyrifos in the little studied neuromuscular transmission of the earthworm ${ }^{[4-6]}$ by comparing it to the well studied neuromuscular transmission in the $\operatorname{frog}^{[7,8]}$.

Earthworm neuromuscular transmission was suggested as cholinergic ${ }^{[9-11]}$ although it varies from cholinergic neuromuscular transmission of the frog in several ways. For instance, a postsynaptic action potential was never evoked in the South American earthworm, Amynthas hawayanus (nee, Pheretima hawayana), muscle membrane by a single threshold, or overthreshold electrical stimulus to its presynaptic nerve in normal earthworm Ringer ${ }^{[5,6]}$. Moreover, a graded spike potential ${ }^{[4-6]}$, which may be equivalent to the frog action potential, can only be evoked by summing two threshold stimuli even when the preparation is in the normal earthworm Ringer. These characteristics suggest that neuromuscular transmission in the earthworm has a much lower excitability than that of the frog.

The present knowledge of the facilitated cholinergic neuromuscular transmission by chlorpyrifos was derived from the whole body homogenized preparations ${ }^{[1-3]}$. This facilitation may be induced by several collateral mechanisms from many parts of the body. A second purpose of this paper is to determine whether facilitation occurs in an isolated neuromuscular preparation in order to exclude mechanisms outside the neuromuscular junction. Assuming that chlorpyrifos facilitates neuromuscular excitability by increasing the available acetylcholine in the neuromuscular junction after inhibiting its hydrolyzation by cholinesterase, it is expected to antagonize the inhibitory effect of curarizing agents such as flaxedil which decreases neuromuscular excitability by blocking acetylcholine binding to the postjunctional receptor and/or by blocking its prejunctional release ${ }^{[12,13]}$. 
Antagonism between these two reagents in earthworm neuromuscular transmission will be compared to their antagonism in the known frog neuromuscular transmission in order to reveal any different cholinesterase mechanism which may cause this low neuromuscular excitability in the earthworm.

Two electrophysiological parameters, the depolarizing rate of the endplate potential evoked by a single threshold stimulus after blocking its action potential by flaxedil and the interstimulus interval of paired threshold stimuli to evoke an action potential after blockage by flaxedil, will be used to measure neuromuscular excitability. As there is little knowledge of neuromuscular transmission in South American frogs of the Leptodactylus and Physalaemus genera, the South American toad, Bufo ichthyricus, will be used in this work because its neuromuscular transmission in normal frog Ringer is known $^{[4]}$ to be similar to that of North American frogs of the genus Rana ${ }^{[7,8]}$.

\section{MATERIALS AND METHODS}

Preparation: Toads, identified as Bufo ichthyricus, were ordered from a local biological supply house. A neuromuscular preparation was made of its sartorius muscle with a stretch of nerve of a few millimeters. It was mounted on a glass slide with its two tendons tied to two elastic bands (Fig. 1a). The preparation on the slide was immersed in $50 \mathrm{cc}$ of normal frog Ringer in a Petri dish for microelectrode recording, while its nerve stump (N, Fig. 1a) could be picked up above the Ringer to be stimulated by a pair of platinum hook electrodes. The evoked response was recorded from its muscle cell membrane (M, Fig. 1a) by a microelectrode (ME, Fig. 1a) observed on an oscilloscope (one circle, Fig. 1a) and photographed.

Earthworms, identified as Amynthas hawayanus, were raised in the laboratory terrarium. The neuromuscular preparation was made of the 21 st - 30th segments of its body wall by slitting the dorsal side, removing the intestine and isolating the $21 \mathrm{st}-25$ th segments of its ventral nerve cord while leaving its 26th - 30th segments attached to the longitudinal muscle layer through three pairs of segmental nerves in each segment. This preparation was pinned, inner side upward, by minute insect pins to a Sylgard-184 floor of a $3.5 \mathrm{~cm}$ diameter Petri dish (Fig. 1b) and covered with 2 cc of normal earthworm Ringer. The five isolated segments of its ventral nerve cord (N, Fig. 1b) could be picked up above the Ringer to be stimulated by a pair of platinum hook electrodes. Evoked responses were recorded from its muscle cell membrane (M, Fig. 1b) by a microelectrode (ME, Fig. 1b), observed with an oscilloscope and photographed. As a standard experimental procedure, stimuli were always delivered in the anterior-posterior direction although no differences in results were found by reversing the direction of stimulation.
Reagents: Normal frog Ringer was routinely prepared in this laboratory. Normal earthworm Ringer was prepared according to Chang ${ }^{[5]}$. Chlorpyrifos is the trade name of 0,0-diethyl 0-(3,5,6-trichloro-2-pyridinyl phosphorothiocate), ordered from FERSOL (São Paulo, Brazil) in $4.8 \times 10^{-1} \mathrm{~g} \mathrm{cc}^{-1}$ concentration. Flaxedil is the trade name of gallamine triethiodide ordered from Sigma-Aldrich (St. Louis, Mo., USA) in $2 \times 10^{-2} \mathrm{~g} \mathrm{cc}^{-1}$ concentration. Concentration of both reagents was changed by injecting the calculated concentrations with a syringe to the known volume of frog, or earthworm, Ringer in the Petri dish without disturbing the stimulation and recording set-up. However, if very high reagent concentrations were needed (e. g., more than $10^{-2} \mathrm{~g} \mathrm{cc}^{-1}$ ), little ionic ingredients will be left in the Ringer solution and our results confounded by the lack of normal ions. Therefore, experiments in these high concentrations were not done.

Instruments: Preparations were observed under a SMXX stereoscopic microscope (Jena, Germany), viewed by transmitted light through a condenser below the floor of a Faraday cage. The stimuli were square wave pulses delivered from a GFE-ISBM-4 function generator (Instituto de Saúde Dr. Bezerra de Menezes, Curitiba, Brazil) with feedback intensity controlled at its output, through platinum hook electrodes to the nerve of toad neuromuscular preparation and to the nerve cord of the earthworm preparation. Intervals between paired stimuli were controlled by a built-in synchronizer in the generator. An intertrial interval of one minute was used in all experiments and controlled manually. Responses from muscle cell membranes of both preparations were recorded by a 6010 glass-tube microelectrode (AM System, Seattle, USA) of 10-20 $\mathrm{M} \Omega$ input impedance filled with $3 \mathrm{M} \mathrm{KCl}$ and attached to a MO-1221S oscilloscope (MINIPA, Taiwan, China) through a P-ISBM-8501 high impedance amplifiers bridge (ISBM, Curitiba, Brazil) and photographed by a C4G camera (Grass, Warwick, RI, USA). The experimental situation is diagramed in Fig. 1a and b.

Experimental procedure: Neuromuscular preparations from sixty toads and sixty earthworms were used. All preparations were submitted to ten minutes of a control session of stimulation and recording in which the ITI was $1.0 \mathrm{~min}$ in normal Ringer. The depolarizing rate was measured by its amplitude expressed in volts divided by time in seconds $\left(\mathrm{V} \mathrm{s}^{-1}\right)$ from toad endplate potential and from earthworm slow potential (Fig. 1c5). The interstimuli interval was the maximal interval in milliseconds (Fig. 1c6) when paired stimuli evoke an action potential summed from two toad endplate potentials, or in the case of the earthworm preparation, a graded spike potential summed from two earthworm slow potentials. After the 10 min control session, preparations were tested in two groups of thirty each in two different solutions. 
The first group of thirty toad and thirty earthworm preparations examined the effect of chlorpyrifos alone. After ten minutes in Ringer solution containing chlorpyrifos, the toad and earthworm preparations received ten single and ten paired stimuli. The second group of thirty toad and thirty earthworm preparations examined the effect of flaxedil alone and the antagonism between chlorpyrifos and flaxedil. After a 10 min adaptation session in Ringer containing flaxedil, ten single and ten paired stimuli were delivered. Ten responses were recorded from each preparation to measure the depolarizing rate and interstimulus interval. Chlorpyrifos was then added to the Ringer containing flaxedil. After a 10 min adaptation session in this solution, ten single and 10 paired stimuli were delivered.

Ten depolarizing measurements and ten interstimulus intervals were averaged from each preparation of each session. They were averaged again among thirty preparations in each session into a single point with standard errors and plotted against their reagent concentrations and shown in Fig. 2 and 3. The statistical significance of the two dependent variables was assessed by a t-test.

\section{RESULTS}

Responses in normal Ringer: Postjunctional muscle cell membrane responses to prejunctional nerve stimuli are different in toad and earthworm neuromuscular preparations in normal Ringer. An action potential (Fig. $1,1 \mathrm{c} 1$ ), was evoked in all thirty toad preparations in normal frog Ringer with a latency of $1.8 \pm 0.5 \mathrm{~ms}$ by a single threshold stimulus of $0.3-0.7 \mathrm{~V}(0.1 \mathrm{~ms})$, intensity to its prejunctional nerve. Paired

stimuli of short interstimulus intervals do not evoke a second action potential (Fig. 1, 1c2) due to the refractory period of the first action potential. An independent second action potential could only be evoked after a long interval. No depolarizing rate or interstimulus interval could be measured from the toad preparations in normal frog Ringer. Moreover, no action potential was evoked by a single stimulus in any earthworm preparation in normal earthworm Ringer. Instead, a slow potential (Fig. 1, 1c5), was evoked in thirty preparations in normal earthworm Ringer with a latency of $12.3 \pm 1.9 \mathrm{~ms}$ by a single threshold stimulus of similar intensity to its prejunctional nerve cord. A depolarizing rate of $0.32 \pm 0.07 \mathrm{~V} \mathrm{~s}^{-1}$ was measured from thirty slow potentials in normal earthworm Ringer (Fig. 2, line 3, point 1). Interstimulus interval of $<15.6$ $\pm 0.9 \mathrm{~ms}$ was also measured from earthworm preparations in normal Ringer (Fig. 3, line 1, point 1).

Effect of chlorpyrifos: The literature indicates chlorpyrifos increase neuromuscular excitability in both toad and earthworm preparations. However, the effect of chlorpyrifos was not demonstrated in our toad preparation because no endplate potential was evoked in normal frog Ringer. The effect of chlorpyrifos was demonstrated in earthworm preparations because its slow potential was evoked in normal earthworm Ringer. The depolarizing rate of earthworm slow potential evoked by a single threshold stimulus increased 19\% from $0.32 \pm 0.07 \mathrm{~V} \mathrm{~s}^{-1}$ in normal Ringer to $0.38 \pm 0.10$ $\mathrm{V} \mathrm{s}^{-1}$ by adding [chlorpyrifos] $]_{\mathrm{o}}=5 \times 10^{-4} \mathrm{~g} \mathrm{cc}^{-1}, 22 \%$ to $0.39 \pm 0.08 \mathrm{~V} \mathrm{~s}^{-1}$ by adding [chlorpyrifos] $]_{\mathrm{o}}=2 \times 10^{-3} \mathrm{~g}$ $\mathrm{cc}^{-1}$ and $31 \%$ to $0.42 \pm 0.9 \mathrm{~V} \mathrm{~s}^{-1}$ by adding [chlorpyrifos] $]_{0}=10^{-2} \mathrm{~g} \mathrm{cc}^{-1}$ to normal earthworm Ringer (Fig. 2, line 3). In [chlorpyrifos $]_{\mathrm{o}}=10^{-2} \mathrm{~g} \mathrm{cc}^{-1}$, a graded spike potential (Fig. 2, line 3, inset) was evoked by a single threshold stimulus in two of thirty preparations for a consecutive two to three minute period. In one of these two graded spike potentials, repetitive discharges are faintly visible (Fig. 2, line 3, arrow).

The interstimulus interval between paired threshold stimuli for evoking a graded spike potential in the earthworm increased $5 \%$ from $15.6 \pm 0.9 \mathrm{~ms}$ in normal Ringer to $16.4 \pm 1.3 \mathrm{~ms}$ by adding [chlorpyrifos] $]_{\mathrm{o}}=5 \mathrm{x}$ $10^{-4} \mathrm{~g} \mathrm{cc}^{-1}, 27 \%$ to $19.8 \pm 0.8 \mathrm{~ms}$ by adding [chlorpyrifos] $]_{\mathrm{o}}=2 \times 10^{-3} \mathrm{~g} \mathrm{cc}^{-1}$ and $23 \%$ to $19.2 \pm 0.4$ $\mathrm{ms}$ by adding [chlorpyrifos] $]_{\mathrm{o}}=10^{-2} \mathrm{~g} \mathrm{cc}^{-1}$ to normal earthworm Ringer (Fig. 3, line 1 and 2).

Effect of flaxedil: Contrary to the effect of chlorpyrifos, flaxedil decreased neuromuscular excitability of both toad and earthworm preparations (Fig. 2). In the toad preparation, an endplate potential with a depolarizing rate of $1.50 \pm 0.19 \mathrm{~V} \mathrm{~s}^{-1}$ was evoked by a single stimulus after its action potential was blocked by adding [flaxedil $]_{\mathrm{o}}=3 \times 10^{-4} \mathrm{~g} \mathrm{cc}^{-1}$ to normal frog Ringer. Increasing [flaxedil]。 to $5 \times 10^{-4} \mathrm{~g}$ $\mathrm{cc}^{-1}$ decreased $25.3 \%$ of the depolarizing rate to $1.12 \pm$ $0.25 \mathrm{~V} \mathrm{~s}^{-1}$ (Fig. 2, first point in line 1 and 2).

The earthworm depolarizing rate of $0.32 \pm 0.07 \mathrm{~V}$ $\mathrm{s}^{-1}$ in normal Ringer (Fig. 2, line 3, point 1 ) decreased $18.7 \%$ to $0.26 \pm 0.08 \mathrm{~V} \mathrm{~s}^{-1}$ by adding [flaxedil] $]_{\mathrm{o}}=3 \mathrm{x}$ $10^{-4} \mathrm{~g} \mathrm{cc}^{-1}$ (Fig. 2, line 4, point 1). Increasing [flaxedil]。 to $5 \times 10^{-4} \mathrm{~g} \mathrm{cc}^{-1}$ further decreased $23.0 \%$ of this depolarizing rate to $0.20 \pm 0.05 \mathrm{~V} \mathrm{~s}^{-1}$ (Fig. 2, line 5, point 1).

Flaxedil also decreased the interstimulus interval of both preparations (Fig. 3).In [flaxedil $]_{\mathrm{o}}=3 \times 10^{-4} \mathrm{~g} \mathrm{cc}^{-1}$, summation of two toad endplate potentials with an interstimulus interval of $1.73 \pm 0.21 \mathrm{~ms}$ (Fig. 3, line 3, point 1) could evoke an action potential (Fig. 1, 1c4). $[\text { Flaxedil }]_{\mathrm{o}}=5 \times 10^{-4} \mathrm{~g} \mathrm{cc}^{-1}$ decreased $59.5 \%$ of this interstimulus interval to $0.70 \pm 0.30 \mathrm{~ms}$ (Fig. 3, line 4, point 1). Further decrease of the interstimulus interval by higher levels of [flaxedil] made the paired threshold stimuli function as a single threshold stimulus ineffective in evoking an action potential. In thirty earthworm preparations, the interstimulus interval between paired stimuli necessary to evoke a graded 
a. Toad neuromuscular preparation

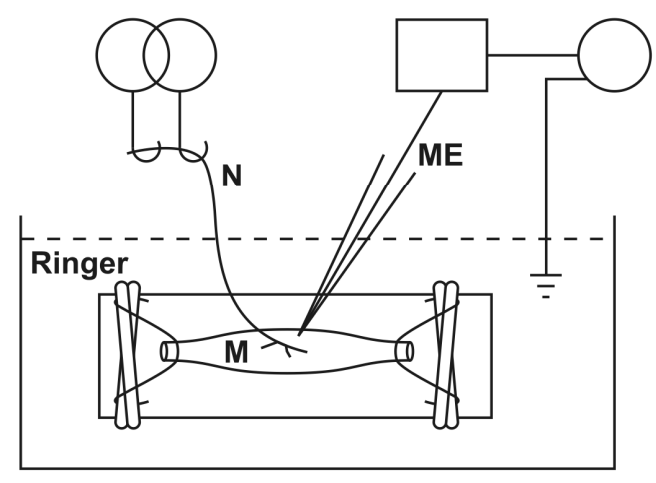

b. Earthworm neuromuscular preparation

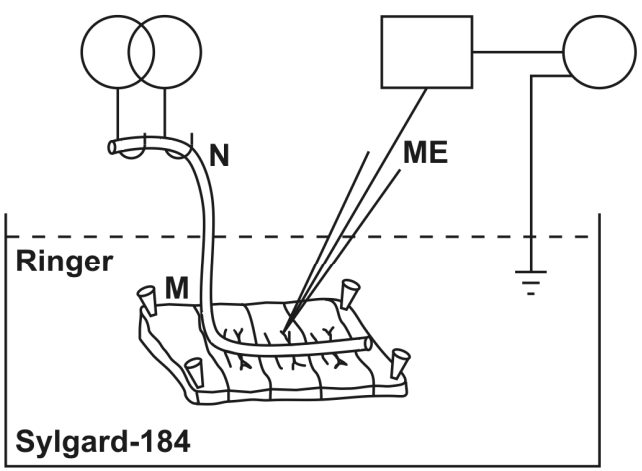

\section{c. Responses}

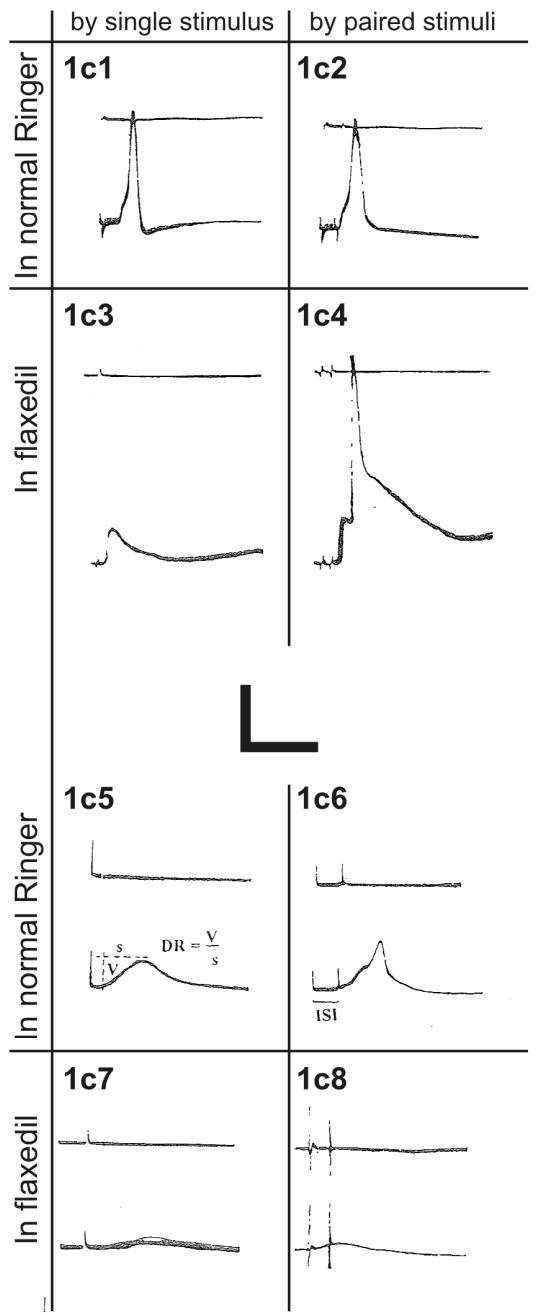

Fig. 1: Stimulation and recording, Toad neuromuscular preparation: M, sartorius muscle with both its tendons tied to two rubber bands at two ends of a glass slide under $50 \mathrm{cc}$ of Ringer solution in a Petri dish. N, nerve lifted above the Ringer by two extracellular platinum hook electrodes and stimulated by a stimulator (two circles). ME, microelectrode inserted into one of the muscle cells for recording the action potential in an oscilloscope (one circle), through a high impedance amplifiers' bridge (rectangle). Earthworm neuromuscular preparation: Same symbols and same set-up as in Fig. 1a, except that the body wall muscle, M, is pinned to the Sylgard-184 floor of the Petri dish under $2 \mathrm{cc}$ of Ringer solution. c. Responses: 1c1. Toad action potential, AP, with overshot above the zero potential. 1c2. Toad AP. 1c3. Toad endplate potential, EPP. 1c4. Toad AP by summating two EPPs . 1c5. Earthworm slow potential, SP. With example measurement of DR. 1c6. Earthworm graded spike potential, GSP, without overshot to the zero potential. With example measurement of ISI. V, voltage. s, second. 1c7. Earthworm SP. 1c8. Two earthworm SPs without GSP. Calibration for Figs. 1c1, 1c2, 1c3 and 1c4, $20 \mathrm{mV}$ and 2 ms. Calibration for Figs. 1c5, 1c6, 1c7 and 1c8, $20 \mathrm{mV}$ and $20 \mathrm{~ms}$

spike potential in normal Ringer without [flaxedil] (Fig.1, 1c6) was $15.6 \pm 2.7 \mathrm{~ms}$ (Fig. 3, line 1, point 1). Adding [flaxedil] o to $3 \times 10^{-4} \mathrm{~g} \mathrm{cc}^{-1}$ decreased $45.3 \%$ of this interstimulus interval to $8.53 \pm 2.12 \mathrm{~ms}$ (Fig. 3, line 2, point 1). Further decrease of the interstimulus interval by higher levels of [flaxedil]。 made the paired threshold stimuli to function as a single threshold stimulus ineffective for evoking a graded spike potential (Fig.1, 1c8).

Antagonism between chlorpyrifos and flaxedil: The depolarizing rate and interstimulus interval decreased by flaxedil in both preparations could be increased again by adding chlorpyrifos. The depolarizing rate of toad endplate potential in [flaxedil $]_{\circ}=3 \times 10^{-4} \mathrm{~g} \mathrm{cc}^{-1}$ was increased $5 \%$ from $1.50 \pm 0.19 \mathrm{~V} \mathrm{~s}^{-1}$ to $1.58 \pm 0.22$ $\mathrm{V} \mathrm{s}^{-1}$ by [chlorpyrifos] $]_{0}=5 \times 10^{-4} \mathrm{~g} \mathrm{cc}^{-1}, 12 \%$ to $1.68 \pm$ $0.34 \mathrm{~V} \mathrm{~s}^{-1}$ by [chlorpyrifos] $]_{0}=2 \times 10^{-3} \mathrm{~g} \mathrm{cc}^{-1}$ and $10 \%$ to $1.65 \pm 0.50 \mathrm{~V} \mathrm{~s}^{-1}$ by [chlorpyrifos] $=10^{-2} \mathrm{~g} \mathrm{cc}^{-1}$ (Fig. 2, line 1). The statistical significance of the increase of these increments was low, $90 \%<\mathrm{P}<95 \%$ $(\mathrm{N}=30+30=60$ in each point $)$, as revealed by a t-test.

The depolarizing rate of toad endplate potential in [flaxedil] $_{0}=5 \times 10^{-4} \mathrm{~g} \mathrm{cc}^{-1}$ increased 3\% from $1.12 \pm$ $0.25 \mathrm{~V} \mathrm{~s}^{-1}$ to $1.16 \pm 0.36 \mathrm{~V} \mathrm{~s}^{-1}$ by [chlorpyrifos] $]_{\mathrm{o}}=5 \mathrm{x}$ $10^{-4} \mathrm{~g} \mathrm{cc}^{-1}, 14 \%$ to $1.28 \pm 0.29 \mathrm{~V} \mathrm{~s}^{-1}$ by [chlorpyrifos]。 


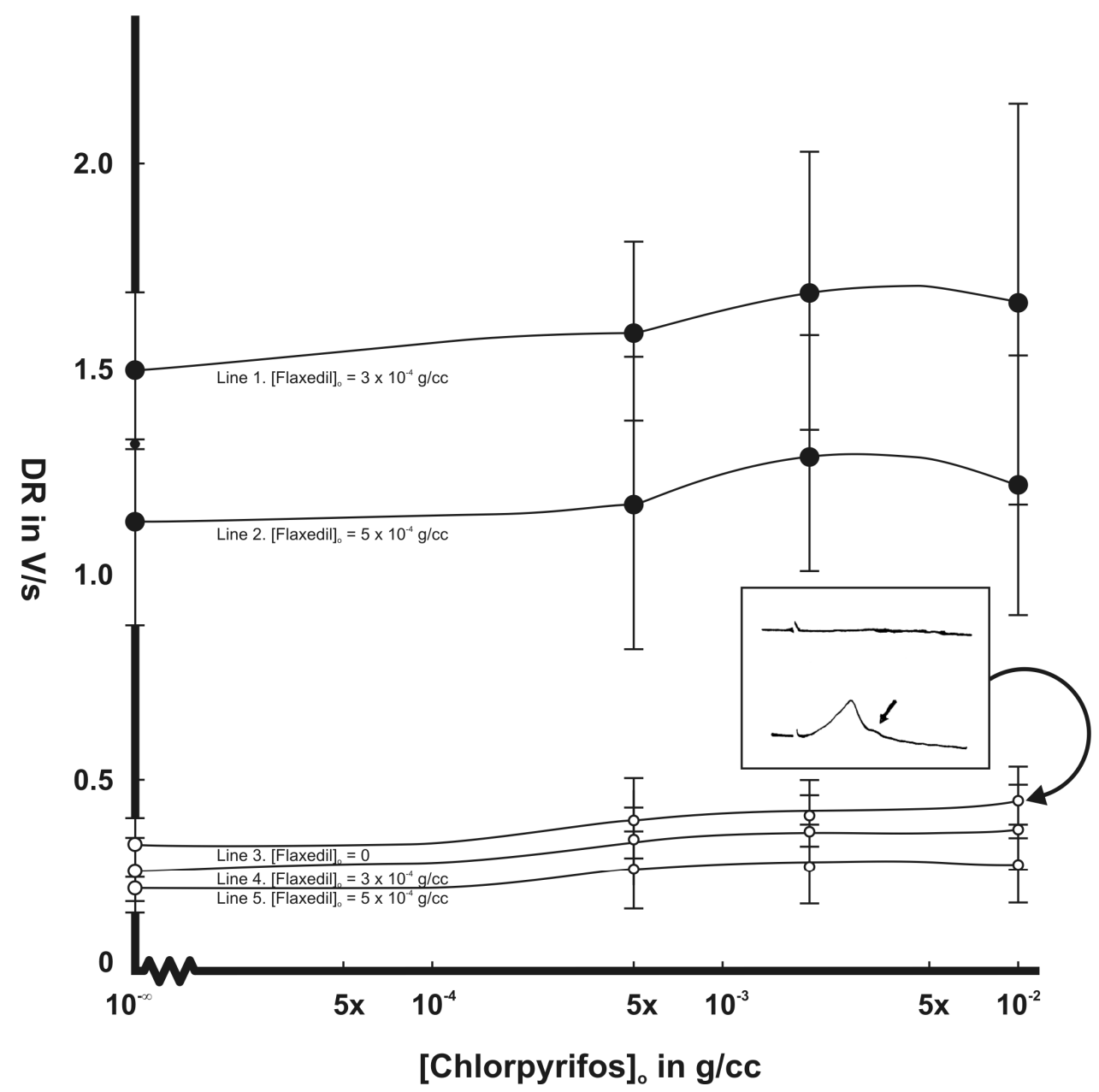

Fig. 2: Depolarizing rate, DR, changes in toad endplate potential, EPP, Ordinate: Depolarizing rate, DR, of endplate potential, EPP, in voltage per second, $\mathrm{V} \mathrm{s}^{-1}$, in arithmetic scale. Abscissa: Extracellular chlorpyrifos concentration, [chlorpyrifos] $]_{\mathrm{o}}$, in gram per cubic centimeter (milliliter), $\mathrm{g} \mathrm{cc}^{-1}$, in logarithmic scale. Extracellular concentrations of flaxedil, [flaxedil], indicated in lines 1 and 2. b. in earthworm slow potential, SP, Ordinate: Depolarizing rate, DR, of slow potential, SP, in voltage per second, $\mathrm{V} \mathrm{s}^{-1}$, in arithmetic scale (Notice: different scale from that in Fig. 2a). Abscissa: Extracellular chlorpyrifos concentration, [chlorpyrifos]o, in gram per cubic centimeter (milliliter), $\mathrm{g} \mathrm{cc}^{-1}$, in logarithmic scale. Extracellular concentrations of flaxedil, [flaxedil], indicated in lines 1, 2 and 3. Inset in line 1, graded spike potential, GSP, evoked by a single stimulus. Arrow, repetitive discharge in low amplitude. Same scale as in Fig.1, 1c5

$=2 \times 10^{-3} \mathrm{~g} \mathrm{cc}^{-1}$ and $7 \%$ to $1.20 \pm 0.32 \mathrm{~V} \mathrm{~s}^{-1}$ by [chlorpyrifos] $]_{0}=10^{-2} \mathrm{~g} \mathrm{cc}^{-1}$ (Fig. 2, line 2). The statistical significance of this increase was also low, $90 \%<\mathrm{P}<95 \%(\mathrm{~N}=60$ in each point) as revealed by a t-test.

The depolarizing rate of earthworm slow potential of $0.32 \pm 0.07 \mathrm{~V} \mathrm{~s}^{-1}$ in normal Ringer without flaxedil (Fig. 2, line 3, point 1) increased $19 \%$ to $0.38 \pm 0.10 \mathrm{~V}$ $\mathrm{s}^{-1}$ by [chlorpyrifos] $]_{0}=5 \times 10^{-4} \mathrm{~g} \mathrm{cc}^{-1}, 22 \%$ to $0.39 \pm$ $0.08 \mathrm{~V} \mathrm{~s}^{-1}$ by [chlorpyrifos] $]_{\mathrm{o}}=2 \times 10^{-3} \mathrm{~g} \mathrm{cc}^{-1}$ and $31 \%$ to $0.42 \pm 0.09 \mathrm{~V} \mathrm{~s}^{-1}$ by [chlorpyrifos] $=10^{-2} \mathrm{~g} \mathrm{cc}^{-1}$ (Fig. 2, line 3). The statistical significance of the increments in these three points was much higher, 99\% $<\mathrm{P}<99.9 \%$ than that in the depolarizing rate of the toad as revealed by a t-test.

In [chlorpyrifos] $]_{\mathrm{o}}=10^{-2} \mathrm{~g} \mathrm{cc}^{-1}$, a graded spike potential (Fig. 2, line 3, inset) was evoked by a single threshold stimulus in two of the thirty preparations for a consecutive two to three minute period. In one of these two graded spike potentials, repetitive discharges are faintly visible (Fig. 2, line 3, arrow). The depolarizing rate of earthworm slow potential decreased to $0.26 \pm$ $0.08 \mathrm{~V} \mathrm{~s}^{-1}$ by [flaxedil] $]_{\mathrm{o}}=3 \times 10^{-4} \mathrm{~g} \mathrm{cc}^{-1}$ increased $27 \%$ to $0.33 \pm 0.08 \mathrm{~V} \mathrm{~s}^{-1}$ by [chlorpyrifos] $]_{0}=5 \times 10^{-4} \mathrm{~g} \mathrm{cc}^{-1}$, $35 \%$ to $0.35 \pm 0.09 \mathrm{~V} \mathrm{~s}^{-1}$ by [Chlorpyrifos] $]_{o}=2 \times 10^{-4} \mathrm{~g}$ $\mathrm{cc}^{-1}$ and $35 \%$ to $0.35 \pm 0.11 \mathrm{~V} \mathrm{~s}^{-1}$ by [Chlorpyrifos] $]_{\mathrm{o}}=$ $10^{-2} \mathrm{~g} \mathrm{cc}^{-1}$ (Fig. 2, line 4). The statistical significance of the increments in these three points was also higher, $99 \%<\mathrm{P}<99.9 \%$ ( $\mathrm{N}=60$ for each point), compared to the depolarizing rate of the toad than that of the toad under the same [flaxedil] $]_{\mathrm{o}}$ conditions.

The depolarizing rate of earthworm slow potential decreased to $0.20 \pm 0.05 \mathrm{~V} \mathrm{~s}^{-1}$ by [flaxedil $]_{\mathrm{o}}=5 \times 10^{-4} \mathrm{~g}$ $\mathrm{cc}^{-1}$, increased $25 \%$ to $0.25 \pm 0.10 \mathrm{~V} \mathrm{~s}^{-1}$ by [chlorpyrifos] $]_{\mathrm{o}}=5 \times 10^{-4} \mathrm{~g} \mathrm{cc}^{-1}, 30 \%$ to $0.26 \pm 0.10 \mathrm{~V}$ $\mathrm{s}^{-1}$ by [Chlorpyrifos $]_{\mathrm{o}}=2 \times 10^{-3} \mathrm{~g} \mathrm{cc}^{-1}$ and $30 \%$ to 


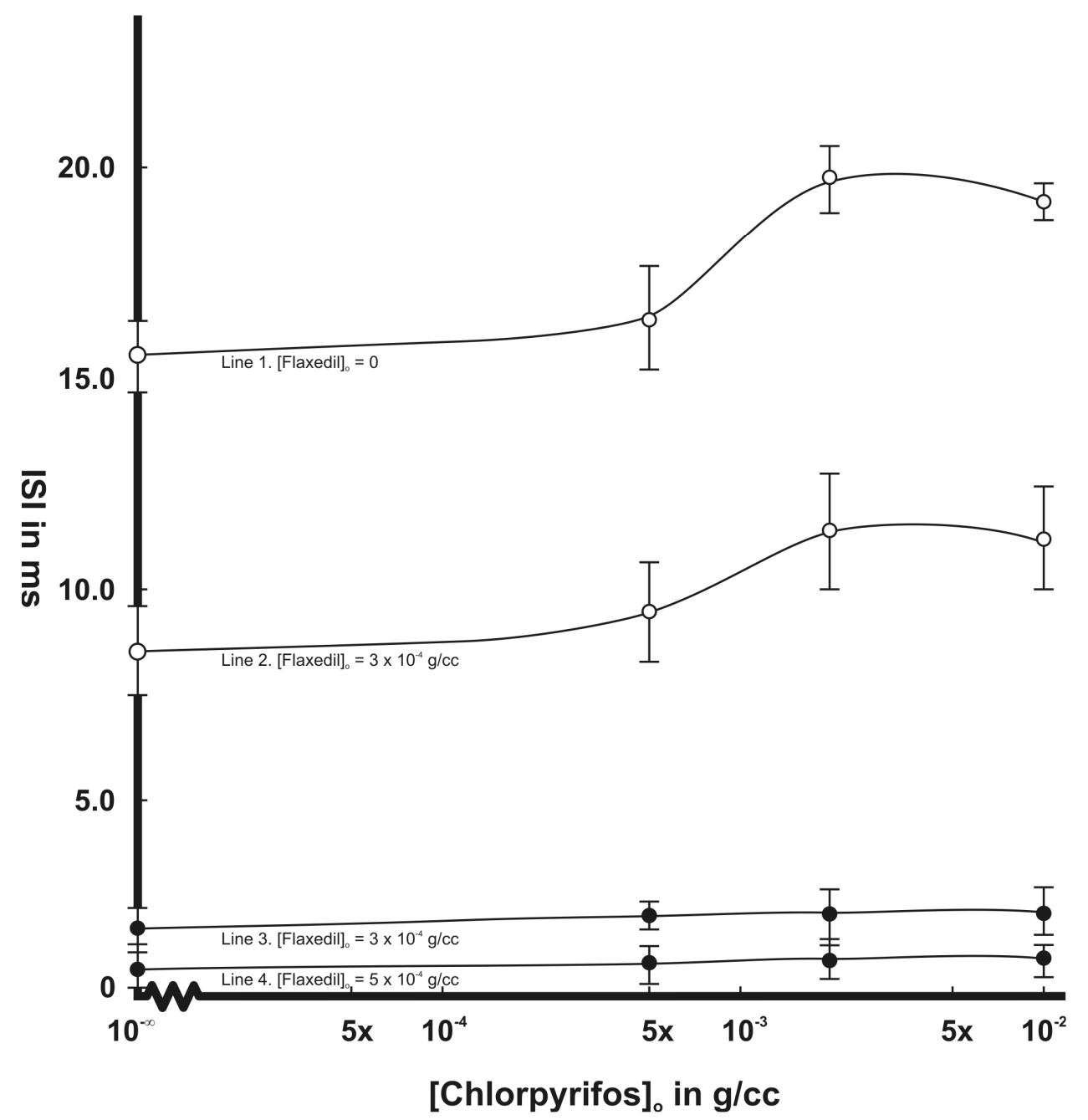

Fig. 3: Interstimulus interval, ISI, changes, For toad action potential, AP, Ordinate: Interstimuli intervals, ISI, between two stimuli, in ms, milliseconds, in arithmetic scale. Abscissa: Extracellular concentration of chlorpyrifos, [chlorpyrifos], in gram per cubic centimeter (milliliter), $\mathrm{g} \mathrm{cc}^{-1}$, in logarithmic scale. Extracellular concentrations of flaxedil, [flaxedil] graded spike potential, GSP, Ordinate: Interstimulus intervals, ISI, between two stimuli, in ms, milliseconds, in arithmetic scale (Notice: different scale from that in Fig. 3a). Abscissa: Extracellular concentration of chlorpyrifos, [chlorpyrifos] $]_{o}$, in gram per cubic centimeter (milliliter), $\mathrm{g} \mathrm{cc}^{-1}$, in logarithmic scale. Extracellular concentrations of flaxedil, [flaxedil], indicated in lines 1 and 2.

$0.26 \pm 0.10 \mathrm{~V} \mathrm{~s}^{-1}$ by [chlorpyrifos $]_{0}=10^{-2} \mathrm{~g} \mathrm{cc}^{-1}$ (Fig. 2, line 5). The statistical significance of the increments in these three points was also higher, $99 \%<\mathrm{P}<99.9 \%$ ( $\mathrm{N}=60$ for each point), compared to the depolarizing rate of the toad than that of the toad under the same [flaxedil]。 conditions. No graded spike potential was evoked by a single stimulus in flaxedil and even the depolarizing rate was increased by chlorpyrifos (Fig. 2, lines, 4 and 5).

The interstimulus interval $=1.73 \pm 0.21 \mathrm{~ms}$ for evoking a toad action potential in [flaxedil $]_{\mathrm{o}}=3 \times 10^{-4}$ $\mathrm{g} \mathrm{cc}^{-1}$, increased only $5 \%$ to $1.82 \pm 0.38 \mathrm{~ms}$ by [chlorpyrifos] $_{\mathrm{o}}=5 \times 10^{-4} \mathrm{~g} \mathrm{cc}^{-1}, 10 \%$ to $1.91 \pm 0.35 \mathrm{~ms}$ by [chlorpyrifos] $]_{o}=2 \times 10^{-3} \mathrm{~g} \mathrm{cc}^{-1}$ and $7 \%$ to $1.85 \pm$ $0.40 \mathrm{~ms}$ by [chlorpyrifos] $]_{\mathrm{o}}=10^{-2} \mathrm{~g} \mathrm{cc}^{-1}$ (Fig. 3, line 1). The statistical significance of these increments was low,
$90 \%<\mathrm{P}<95 \%(\mathrm{~N}=30+30=60$ in each point $)$, as revealed by a t-test.

The interstimulus interval $=0.70 \pm 0.13 \mathrm{~ms}$ for evoking a toad action potential in [flaxedil $]_{\mathrm{o}}=5 \times 10^{-4}$ $\mathrm{g} \mathrm{cc} \mathrm{cc}^{-1}$ increased $9 \%$ to $0.76 \pm 0.25 \mathrm{~ms}$ by [chlorpyrifos] $]_{\mathrm{o}}=5 \times 10^{-4} \mathrm{~g} \mathrm{cc}^{-1}, 14 \%$ to $0.80 \pm 0.24 \mathrm{~ms}$ by [chlorpyrifos] $]_{\mathrm{o}}=2 \times 10^{-3} \mathrm{~g} \mathrm{cc}^{-1}$ and $16 \%$ to $0.81 \pm$ $0.30 \mathrm{~ms}$ by [chlorpyrifos] $]_{0}=10^{-2} \mathrm{~g} \mathrm{cc}^{-1}$ (Fig. 3, line 4). The statistical significance of these three points was also low, $90 \%>\mathrm{P}>95 \%(\mathrm{~N}=60$ in each point $)$, as revealed by a t-test.

The interstimulus interval $=15.6 \pm 0.9 \mathrm{~ms}$ for evoking the earthworm graded spike potential in normal Ringer without flaxedil increased $5 \%$ to $16.4 \pm 1.3 \mathrm{~ms}$ by [chlorpyrifos $]_{\mathrm{o}}=5 \times 10^{-4} \mathrm{~g} \mathrm{cc}^{-1}$. [Chlorpyrifos $]_{\mathrm{o}}=2$ x $10^{-3} \mathrm{~g} \mathrm{cc}^{-1}$, increased it $27 \%$ to $19.8 \mathrm{~ms} \pm 0.8 \mathrm{~ms}$ and 
[chlorpyrifos] $]_{\mathrm{o}}=10^{-2} \mathrm{~g} \mathrm{cc}^{-1}$, increased it $23 \%$ to $19.2 \pm$ $0.4 \mathrm{~ms}$ (Fig. 3, line 1). Although the increment by [chlorpyrifos] $]_{o}=5 \times 10^{-4} \mathrm{~g} \mathrm{cc}^{-1}$ was of low significance, $90 \%<\mathrm{P}<95 \%(\mathrm{~N}=30+30=60)$, as revealed by a ttest, significant results were found in the next two points by [Chlorpyrifos] $]_{0}=2 \times 10^{-3} \mathrm{~g} \mathrm{cc}^{-1}$ and by [chlorpyrifos] $_{\mathrm{o}}=10^{-2} \mathrm{~g} \mathrm{cc}^{-1}(99 \%<\mathrm{P}<99.9 \% ; \mathrm{N}=60$ for each point).

The interstimulus interval $=8.53 \pm 2.12 \mathrm{~ms}$ for evoking the earthworm graded spike potential in [flaxedil] $_{\mathrm{o}}=3 \times 10^{-4} \mathrm{~g} \mathrm{cc}^{-1}$ increased little, $9 \%$, to $9.3 \pm$ $1.2 \mathrm{~ms}$ by [chlorpyrifos] $=5 \times 10^{-4} \mathrm{~g} \mathrm{cc}^{-1}$. [Chlorpyrifos] $_{\mathrm{o}}=2 \times 10^{-3} \mathrm{~g} \mathrm{cc}^{-1}$ increased it $31 \%$ to $11.22 \pm 1.4 \mathrm{~ms}$ and [chlorpyrifos] $]_{o}=10^{-2} \mathrm{~g} \mathrm{cc}^{-1}$ increased it $29 \%$ to $11.0 \pm 1.3 \mathrm{~ms}$ (Fig. 3, line 2). Similarly, the increase by [chlorpyrifos] $=5 \times 10^{-4} \mathrm{~g}$ $\mathrm{cc}^{-1}$ was of low significance, $90 \%<\mathrm{P}<95 \%(\mathrm{~N}=60)$, as revealed by a t-test. Statistical significance was found in the next two points by [Chlorpyrifos] $]_{0}=2 \mathrm{x}$ $10^{-3} \mathrm{~g} \mathrm{cc}^{-1}$ and by [chlorpyrifos] $]_{\mathrm{o}}=10^{-2} \mathrm{~g} \mathrm{cc}^{-1}(99 \%<\mathrm{P}$ $<99.9 \% ; \mathrm{N}=60$ for each point).

\section{DISCUSSION}

Only the effect of chlorpyrifos on neuromuscular transmission was studied in this article. All other collateral effects of chlorpyrifos mentioned in the literature ${ }^{[1-3]}$ were not studied in these two isolated neuromuscular preparations. Furthermore, only the effect of chlorpyrifos on two parameters, depolarizing rate and interstimuli interval of endplate potential and of slow potential, was studied. Both endplate potential and slow potential are postsynaptic events. Therefore, the possible effects of chlorpyrifos on earthworm extrasynaptic action potentials were also excluded from this study ${ }^{[14]}$. Previous work $^{[4-6]}$ reported a long neuromuscular latency, or junctional delay, in the earthworm. In the present work, the latency, or junctional delay, measured in the earthworm preparations (12.3 ms) in normal Ringer was more than six times longer than that $(1.8 \mathrm{~ms})$ in the toad preparations under threshold flaxedil. The depolarizing rate $\left(0.32 \mathrm{~V} \mathrm{~s}^{-1}\right)$ measured in earthworm slow potential in normal Ringer is one fifth of that $\left(1.50 \mathrm{~V} \mathrm{~s}^{-1}\right)$ of the toad (Fig. 2) and the interstimulus interval (15.6 ms) required for evoking a graded spike potential in the earthworm preparations is nine times longer than that $(1.75 \mathrm{~ms})$ required for evoking an action potential in the toad preparations under threshold flaxedil (Fig. 3). These differences indicate that either the combination of acetylcholine to its receptor is five to nine times slower in the earthworm than that in the toad, or the hydrolysis of acetylcholine by cholinesterase is five to nine times faster in the earthworm than that in the toad.

If Fig. 2 and 3 are looked vertically along the ordinate, it is clear that flaxedil decreased the depolarizing rate (Fig. 2) and interstimulus interval
(Fig. 3) in both toad and earthworm as predicted ${ }^{[4-6,11-}$ ${ }^{13]}$. When the graphs are examined horizontally along the abscissa, the first impression is that chlorpyrifos increased the depolarizing rate (Fig. 2) and interstimulus interval (Fig. 3) in both preparations by its antagonism to flaxedil as proposed in the Introduction. However, when the mean and standard errors of each point are examined, wide spreading and overlapping our found among the depolarizing rates and interstimulus intervals in the toad preparation and this gives the impression that chlorpyrifos inhibits cholinesterase little, or not at all, in the toad. In the earthworm, with the exception of the first two points in Fig. 3 (line 1 and 2), the mean and standard errors of the depolarizing rate and interstimulus interval are widely spread and overlapping along the chlorpyrifos axis. We therefore conclude that chlorpyrifos increases these two dependent variables in the earthworm. These different reactions to chlorpyrifos suggest that cholinesterase has different characters or structures in toad and earthworm.

If we postulate that failure to evoke the earthworm graded spike potential in normal earthworm Ringer is due to the low depolarizing rate $\left(0.32 \mathrm{~V} \mathrm{~s}^{-1}\right)$ in its slow potential, increasing the depolarizing rate to $0.42 \mathrm{~V} \mathrm{~s}^{-1}$ by [chlorpyrifos] $]_{0}=10^{-2} \mathrm{~g} \mathrm{c}^{-1} \mathrm{c}$ (Fig. 2, line 3, inset) was also ineffective; in only 2 of 30 preparations was a graded spike potential evoked. It may be argued, however, that had chlorpyrifos increased further, more cholinesterase will be inhibited and more graded spike potentials would have been evoked. Concentration higher than $10^{-2} \mathrm{~g} \mathrm{cc}^{-1}$ is pharmacologically unreasonable. Another conclusion is thus drawn that chlorpyrifos is not very effective in inhibiting cholinesterase in toad neuromuscular preparations but it is also insufficient in enhancing earthworm neuromuscular excitability from graded to all-or-none, compared to prostigmine which enhanced its excitability readily within a moderate concentration range (see Fig. 7 in reference 6). Notice that, even the highest depolarizing rate $\left(0.42 \mathrm{~V} \mathrm{~s}^{-1}\right)$ ever induced in earthworm slow potentials by chlorpyrifos is still far too low compared to the depolarizing rate $\left(1.50 \mathrm{~V} \mathrm{~s}^{-1}\right)$ in toad endplate potential without chlorpyrifos.

The effective [chlorpyrifos] ${ }_{0}$ s determined in this work for earthworm cholinesterase inhibition were much higher than what would have induced a $L_{50}=$ $0.063 \mu \mathrm{g} \mathrm{cm}^{-2[15]}$ which was even lower than that would have been induced by prostigmine ${ }^{[6]}$. These high chlorpyrifos concentrations recorded in our experiments were probably due to the use of cholinesterase from neuromuscular junction alone instead of from whole body homogenized preparations ${ }^{[1-3,15]}$. The earthworm neuromuscular transmission would have been converted from graded to all-or-none if a high cholinesterase inhibition velocity such as $\mathrm{K}_{\mathrm{i}}=4.2 \times 10^{-6} \mathrm{M}$, was induced by chlorpyrifos ${ }^{[15]}$. In addition to the suggested structural difference, another possible explanation to 
this low cholinesterase inhibition is that cholinesterase may be tightly bound in earthworm neuromuscular junction that is difficult to reach in situ by chlorpyrifos but easily to diffuse into an artificial medium when homogenized.

\section{REFERENCES}

1. Bushnell, P.J., K.L. Kelly and T.R. Ward, 1994. Repeated inhibition of cholinesterase by chlopyrifos in rats: Behavioral, neurochemical and pharmacological indices of tolerance. J. Pharma. Experi., 270: 15-25.

2. Betancourt, A.M. and R.L. Carr, 2004.The effect of chlorpyrifos and chlorpyrifos-oxon on brain cholinesterase, muscarinic receptor binding and neurotrophin levels in rats following early postnatal exposure. Toxicol. Sci., 77: 63-71.

3. Tilak, K.S., K. Veeraiah and D.K. Rao, 2005. The effect of chlorpyrifos, an organophosphate, in acetylcholinesterase activity in freshwater fishes. J. Environ. Biol., 26: 73-77.

4. Chang, Y.C. and Z. Bruno, 1970. The effect of piperazine on toad and earthworm muscle membrane potentials. Pharmacology, 4: 143-151.

5. Chang, Y.C., 1975a. Two groups of resting potential from the earthworm (Pheretima hawayana, R.) longitudinal muscle cell membrane. Comp. Biochem. Physiol., 51a: 231-235.

6. Chang, Y.C., 1975b. The endplate and graded potentials from the neuromuscular system of the earthworm, Pheretima hawayana, R. Comp. Biochem. Physiol., 51a: 237-240.
7. Fatt, P., 1959. Skeletal Neuromuscular Transmission. In: Handbook of Physiology (Ed. M. Hall) pp: 199-213. American Physiological Society, Bethesda, Maryland.

8. Katz, B., 1966. Nerve, muscle and synapse. McGraw-Hill, New York.

9. Wu, K.S., 1939. The action of drugs, especially acetylcholine, on the annelid body wall (Lumbricus terrestris). J. Exp. Biol., 16: 251-257.

10. Botsford, E.F., 1941. The effects of physostigmine on the response of earthworm body wall preparations to successive stimuli. Biol. Bull., 80: 299-314.

11. Hidaka, T., Y. Ito, H. Kuriyama and N. Tashiro, 1969. Neuromuscular transmission in the longitudinal layer of the somatic muscle in the earthworm. J. Exp. Biol., 150: 417-430.

12. Eccles, J.C., B. Katz and S.W. Kuffler, 1942. Effect of eserine on neuromuscular transmission. J. Neurophysiol., 5: 211-230.

13. Koltgen, D., H. Brinkmeier and H. Kockusch, 1991. Myotonia and neuromuscular transmission in the mouse. Muscle and Nerve, 14: 775-780.

14. Hidaka, T., Y. Ito and H. Kuriyama, 1969. Membrane properties of the somatic muscle (obliquely striated muscle) of the earthworm. J. Exp. Biol., 50: 387-403.

15. Rao, J.V., Y.S. Pavan and S.S. Madhavendra, 2003. Toxic effects of chlorpyrifos on morphology and acetylcholinesterase activity in the earthworm, Eisenia foetida. Exotox. Enviro. Safety, 54: 296-301. 